\title{
Mineralogical composition of Rrogozhina aquifer medium, Western Albania
}

Enkeleida Beqiraj ${ }^{1}$, Dritan Siliqi ${ }^{2}$, Francesco Capitelli ${ }^{3}$, Arjan Beqiraj ${ }^{1}$, Suada Luzati $^{4}$

${ }^{1}$ Polytechnic University Of Tirana, Dept. Earth Sciences, Tirana, Albania, ${ }^{2}$ Istituto di Cristallografia, Consiglio Nazionale delle Ricerche, Bari, Italy, ${ }^{3}$ Istituto di Cristallografia, Consiglio Nazionale delle Ricerche, Roma, Italy, ${ }^{4}$ Centres of Agricultural Technology Transfer, Fushe Kruje, Albania

E-mail: ea_beqiraj@yahoo.com

The Rrogozhina aquifer extending over the pre-Adriatic Depression of Albania is hosted in Pliocene molasse formations which consist of water-bearing sandstone and conglomerate intercalated with impermeable siltstone and mudstone. The mainly magmatic - carbonatic composition of aquifer medium determined a mostly HCO3-Mg-Ca hydrochemical type of groundwater composition [1]. The groundwater of the Rrogozhina aquifer also contains high concentrations of iron that ranges from 0.2 wt. \% up to $2.5 \mathrm{wt}$. \% FeO [2]. Iron is more frequent and higher in the sandstone-related groundwater than in that hosted by conglomerates [2]. Both the hydrochemical composition and iron content in groundwater are closely related with mineralogical composition of the aquifer medium. To better understand the role of this later on the groundwater chemistry and, especially the uncommon high content of iron in groundwater, five samples were randomly taken: $t w o(R r-1, R r-5)$ from conglomerates and three ( $\mathrm{Rr}-2, \mathrm{Rr}-3, \mathrm{Rr}-4)$ from sandstones. The mineralogical composition of silt and clay fractions of the samples were tested by X-Ray Diffraction (XRD) and Scan Electron Microscopy - Energy Dispersive Spectroscopy (SEMEDS). Chemical analysis of major elements in the silt and clay fractions were performed, as well. The X-ray diffraction analysis revealed that quartz and Ca-carbonate (less $\mathrm{Mg}$-carbonate) are the major mineral constituents of both silt and clay fractions, while to less contents are feldspar and pyroxene. The semi-quantitative calculations of XRD results made through QUALX2 [3] software found that $\mathrm{CaCO} 3$ and $\mathrm{SiO} 2$ range from 17 to $56 \%$ and from 33 to $63 \%$, respectively. Feldspar and pyroxene together occurs below 20\% except in sample $\mathrm{Rr}-4$ where their content reaches up to $30 \%$. Concerning iron phases, the XRD evidenced only the presence of pigeonite $(\mathrm{Ca}, \mathrm{Mg}, \mathrm{Fe})(\mathrm{Mg}, \mathrm{Fe}) \mathrm{Si} 2 \mathrm{O} 6$, which shows the highest peak for that angle $2 \theta=29.50^{\circ}$. SEM - EDS analysis not only reconfirmed the major phases contents in both clay and silt samples, but evidenced the presence of high-iron phyllosilicates like chamosite (Fe2+, Mg)5Al(AISi3O10)(OH)8) and pigeonite, as well. The presence of limonite was assumed, which was not evidenced by XRD due to its amorphous state. The chemical analysis of major elements fit very well with mineralogical composition found by XRD and SEM-EDS analysis. Thus, higher (29.01wt\%) $\mathrm{CaO}$ content in the sample RR-1, against 9.00 wt\% in other samples, correlates with higher calcite found by XRD, whereas higher FeOtot in samples $\mathrm{Rr}-3$ and $\mathrm{Rr}-5$ (10.46wt\% and $11.48 \mathrm{wt} \%$, respectively) correlate with the presence of iron mineral phases found by SEM-EDS analysis.

[1] Beqiraj, A. \& Kumanova, Xh. (2010). 7th Int. Symp.on the Eastern Mediterranean Geol. Abstract book, p.172.

[2] Beqiraj, A. \& Beqiraj (Goga), E. (2011). Studia UBB Geologia, 56 (2), 25 - 30.

[3] Altomare, A. et.al. (2015). J. Appl. Cryst. 48, 598-603.

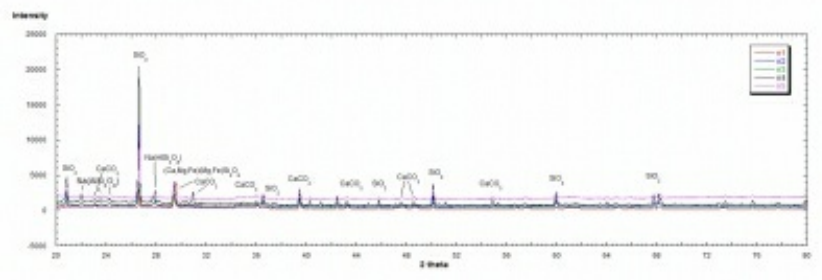

Keywords: aquifer medium, mineralogical composition, iron phases 